JOURNAL of

MAINE MEDICAL CENTER Journal of Maine Medical Center

Volume 2

Issue 1 Volume 2, Issue 1 (January 2020)

Article 5

2020

\title{
Changes in hospital utilization by individuals experiencing homelessness after engaging with interdisciplinary, low-barrier healthcare services in Portland, Maine
}

\author{
Sarah Hemphill BA \\ Tufts University School of Medicine
}

Et al.

Follow this and additional works at: https://knowledgeconnection.mainehealth.org/jmmc

Part of the Clinical and Medical Social Work Commons, Community Health and Preventive Medicine Commons, and the Interprofessional Education Commons

\section{Recommended Citation}

Hemphill, Sarah BA; Normandin, Adam MD, MS; and Rothenberg, Debra MD, PhD (2020) "Changes in hospital utilization by individuals experiencing homelessness after engaging with interdisciplinary, lowbarrier healthcare services in Portland, Maine," Journal of Maine Medical Center. Vol. 2 : Iss. 1 , Article 5. Available at: https://knowledgeconnection.mainehealth.org/jmmc/vol2/iss1/5 https://doi.org/10.46804/ 2641-2225.1038

The views and thoughts expressed in this manuscript belong solely to the author[s] and do not reflect the opinions of the Journal of Maine Medical Center or MaineHealth.

This Original Research is brought to you for free and open access by Maine Medical Center Department of Medical Education. It has been accepted for inclusion in the Journal of Maine Medical Center by an authorized editor of the MaineHealth Knowledge Connection. For more information, please contact Dina McKelvy mckeld1@mmc.org.

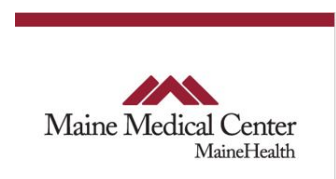


Changes in hospital utilization by individuals experiencing homelessness after engaging with interdisciplinary, low-barrier healthcare services in Portland, Maine

\section{Acknowledgements}

Kathleen Fairfield Tina Holt Amy Haskins

Authors

Sarah Hemphill BA; Adam Normandin MD, MS; and Debra Rothenberg MD, PhD 


\title{
Hospital Utilization by Individuals Experiencing Homelessness after Engaging with Interdisciplinary, Low-Barrier Health Care Services in Portland, Maine
}

\author{
Sarah Hemphill, BA, ${ }^{1}$ Adam Normandin, MD, MS, ${ }^{2}$ Debra Rothenberg, MD, $\mathrm{PhD}{ }^{2}$ \\ ${ }^{1}$ Tufts University School of Medicine, Boston, MA, ${ }^{2}$ Department of Family Medicine, Maine Medical Center, Portland, ME
}

\begin{abstract}
Introduction: $\quad$ The Preble Street Learning Collaborative (PSLC) aims to address unmet health care needs of people experiencing homelessness. The PSLC provides low-barrier health care near many social services in Portland, Maine. We evaluated the impact of the PSLC by describing the demographic characteristics and patterns in hospital utilization of patients served by the PSLC.
\end{abstract}

Methods: $\quad$ We performed a retrospective chart review of 888 patients with PSLC encounters between January 2017 and July 2018. We collected data from electronic health records that included one year before and after each patient's first PSLC encounter. We stratified patients based on the number of emergency department (ED) visits in the year before the first PSLC encounter. Non-utilizers $(n=392)$ made 0 visits, low-utilizers $(n=356)$ made 1-3 visits, high-utilizers $(n=116)$ made 4-9 visits, and very-high-utilizers $(n$ $=24$ ) made $\geq 10$ visits.

Results: $\quad$ Pre- to post-PSLC engagement, we found significant increases in the mean number of ED visits (0 to $0.96, P<.001)$ and hospital admissions ( 0 to $0.15, P<.001)$, as well as length of stay (0 to 1.16 days, $P<.001)$ for non-utilizers. Significant decreases in mean ED visits were seen for high-utilizers (5.55 to $4.12, P=.005)$ and very-high-utilizers (15.0 to 5.92, $P<.001)$.

Conclusions: PSLC engagement was associated with decreased ED visits by high- and very-high-utilizers, and increased visits by non-utilizers. Health systems may reduce ED utilization by providing low-barrier access to health care in clinics focused on serving individuals experiencing homelessness.

Keywords: $\quad$ hospital utilization, homeless, low-barrier health care, social work, interdisciplinary

ndividuals experiencing homelessness suffer a disproportionately high burden of disease, often delay seeking medical care, and have many unmet health care needs. ${ }^{1-5}$ Furthermore, homelessness contributes to a 7.9-11.9-fold increase in all-cause mortality. ${ }^{6-8}$ Health care expenditures associated with treating those experiencing homelessness are 3.8-fold higher than housed persons, ${ }^{7,9}$ and people experiencing homelessness are more likely to be high-utilizers of the emergency department (ED). . $3,10-14$

Correspondence: Adam Normandin, MD, MS

Outreach Director, Maine Medical Center

Preble Street Learning Collaborative

272 Congress St, Portland ME 04101

Normaa1@mmc.org
In Maine, the number of people experiencing homelessness grew 37\% from 2010 to $2019 . .^{15}$ In 2017, almost half of these individuals were located in Portland. ${ }^{16}$ Best practices in engaging this population in health care suggest that services must be low-barrier and highly coordinated with other community entities. ${ }^{17}$ In 2017, the PSLC was established in response to a hospital and community needs assessment. The report cited 1) a lack of formal training in health care disparities in hospital residency programs ${ }^{18}$ and 2) a community's need for low-barrier access to health services, care coordination, and a new point of entry to the health system for people experiencing homelessness. Health care and community leaders sought mutual benefit in the PSLC. ${ }^{19}$ The PSLC is staffed by a full-time nurse practitioner, six social workers, and 
a health services coordinator. Implied by its title, the "Learning Collaborative" pairs this staff with residents in medicine, family medicine, emergency medicine, psychiatry, and pharmacy to provide interdisciplinary care. The PSLC identifies and meets the basic needs of all who walk in the door (e.g., wound care, minor infections, counseling, shortterm respite from the street, insurance applications, transportation to medical appointments) in an effort to engage high-risk patients and connect them with long-term medical homes. The PSLC is strategically located near key community resources, such as a soup kitchen, shelter, general assistance, and the city's Federally Qualified Health Center. This location is readily accessible to those experiencing homelessness and staying at the shelter, which largely defines the population served by the PSLC, though services are accessible to anyone. The PSLC also uses a shared electronic health record (EHR) with the hospital system, enabling improved care coordination and communication with other providers. There is currently no cost to patients who receive care at the PSLC.

This study characterized the PSLC patient population and evaluated changes in their ED and hospital utilization before and after any kind of engagement with the PSLC. We hypothesized that by meeting basic unmet health care needs, the PSLC can reduce overutilization of acute hospitalbased care.

\section{METHODS}

We present a retrospective cohort study of EHR data of adults experiencing homelessness in Portland, Maine who were seen one or more times by PSLC providers between January 2017 and July 2019. The Maine Medical Center (MMC) institutional review board granted approval of this study.

\section{Study population}

All patients with a documented encounter at the PSLC were initially included in the study. Encounters included office visits, off-site visits, patient outreach, clinical updates, or telephone calls documented in the EHR. The PSLC went live with MMC's EHR in January 2018. A separate secure database stored PSLC encounter records before January 2018. We used patient identifiers to link that database to unique Medical Record Numbers (MRN) in the EHR.
Patients were excluded from the final study cohort if 1) we could not link their identifiers to an MRN, 2) one full year had not elapsed between their first PSLC encounter and data extraction, or 3) they passed away during the year following their first PSLC encounter.

\section{Data collection}

EHR data were extracted on all eligible individuals on July 18, 2019. Demographic data collected included age, gender, ethnicity/race, preferred language, insurance status at first encounter, insurance status as of July 2019 , and employment status. All demographic data were taken from the EHR and could have been entered by any provider. These data may or may not have been selfreported. The first PSLC encounter was the date of the first documented encounter of any kind that the individual had with the PSLC. Hospital encounter data included all ED visits and subsequent hospital admissions, if applicable. Visits to any ED or urgent care in our health care system were included, which we collectively refer to as "ED visits." Thus, hospital utilization was not limited to hospitals in the immediate Portland area. For each individual, the number of ED visits, the number of hospital admissions, and the total length of stay (LOS) in the hospital, in days, were counted for 365 days before and 365 days after each patient's first PSLC encounter. Because the times of PSLC encounters were not consistently available, ED visits that occurred on the same day as the first PSLC encounter were counted as occurring after the first PSLC encounter. Individuals with no ED visits or hospital admissions were assigned a value of 0 for all fields and were included in the analysis.

\section{Data analysis}

All data were analyzed using $\mathrm{R}$ with the packages readr, dplyr, and lubridate. ${ }^{20}$ Statistical significance was determined using paired two-tailed t-tests with significance level $\alpha=0.05$. Consistent with previous studies on ED utilization, we divided the cohort into four subgroups based on baseline ED utilization, or the number of ED visits during the year before the patient's first PSLC encounter. ${ }^{21}$ Non-utilizers had no ED visits during the year before first PSLC encounter, low-utilizers had 1-3 visits, high-utilizers had 4-9 visits, and very-high-utilizers had $\geq 10$ ED visits. Means reflect all members of each group. 


\section{RESULTS}

A total of 1,554 patients had encounters at the PSLC since it opened in January 2017. Of these, 17 were excluded because their PSLC record could not be matched to an EHR MRN. Another 649 were excluded because a full year had not elapsed between their first PSLC encounter and the time of data extraction, or they passed away within 1 year of the first encounter. Thus, 888 patients were included in the final study cohort (Figure 1).

The study population was predominantly younger than 50 years, male, white, English-speaking, unemployed, and insured by Medicaid or Medicare (Table 1). Specifically, 582 patients $(65 \%)$ were younger than 50 years, and 877 (98\%) were younger than 70 years. Also, 579 patients $(65 \%)$ were male, and 743 (84\%) were white. Further, 826 patients (93\%) had English as their preferred language. Compared to each patient's first PSLC encounter (July 2018 or before), there was a lower rate of uninsurance (38\% versus $20 \%$ ) and a higher proportion of individuals with Medicare or Medicaid (52\% versus $63 \%$ ) as of July 2019.

Table 2 shows hospital utilization rates during the year before and after the first PSLC encounter. Overall, the study cohort had a higher total number of ED visits (1597 pre-PSLC versus 1641 postPSLC), hospital admissions (166 versus 187) and LOS in the hospital (1522 versus 1804 days). For non-utilizers $(n=392)$, there was a significant increase in the mean number of ED visits $(0$ [standard deviation; 0] to 0.96 [1.58], $P<.001)$, number of hospital admissions (0 [0] to 0.15 [0.49], $P<.001)$, and LOS (0[0] to 1.16[5.26], $P<.001)$. Low-utilizers $(n=356)$ did not show any significant changes. High utilizers $(n=116)$ showed significant decreases in ED visits (5.55 [1.61] to 4.12 [5.57], $P=.0054)$ and admissions (0.59 [1.07] to 0.28 [0.69], $P=.0018)$. Very-high-utilizers $(n=24)$ had

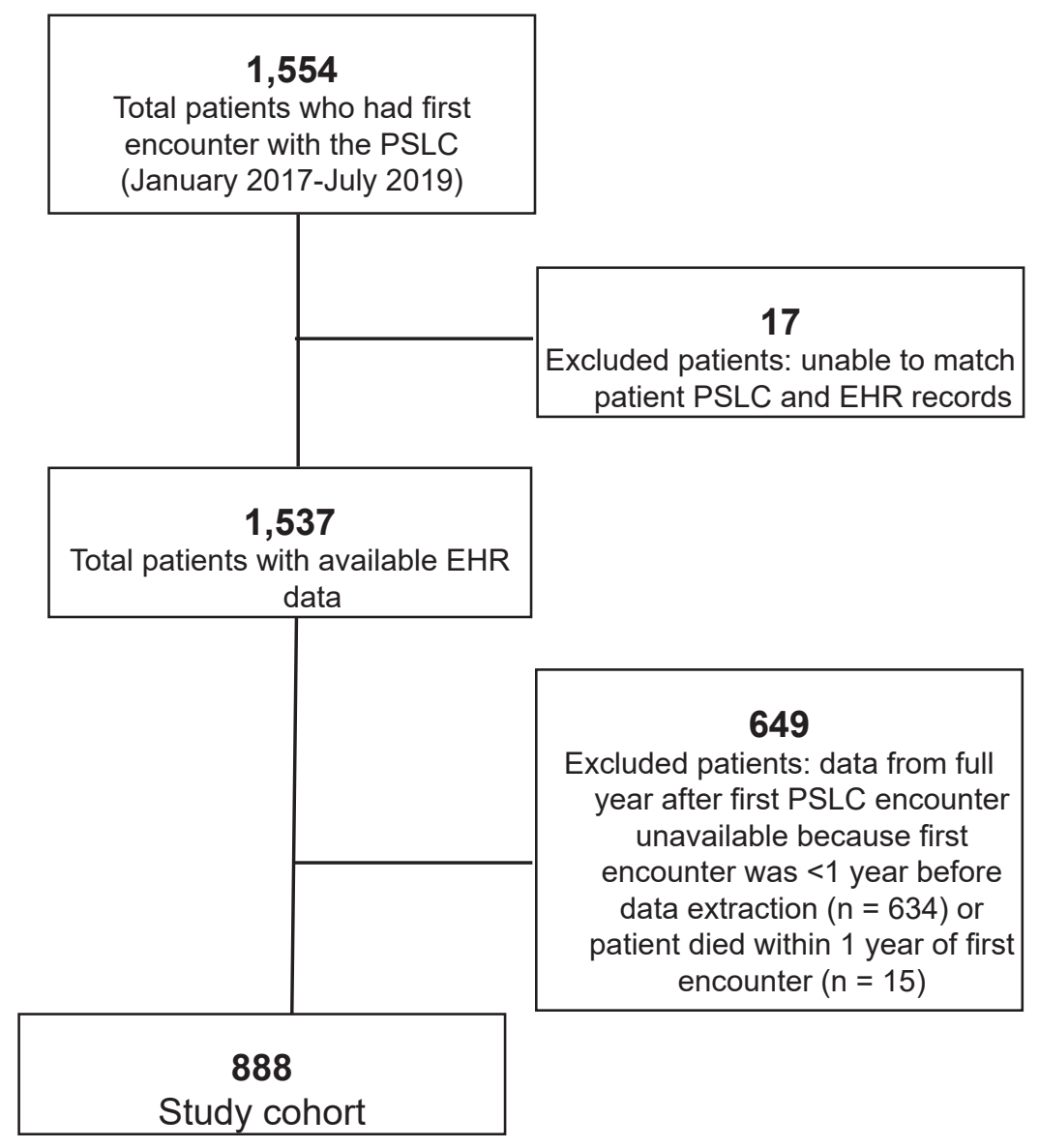

Figure 1. Study cohort. PSLC, Preble Street Learning Collaborative; EHR, electronic health record 
Table 1. Characteristics of the Study Cohort $(n=888)$

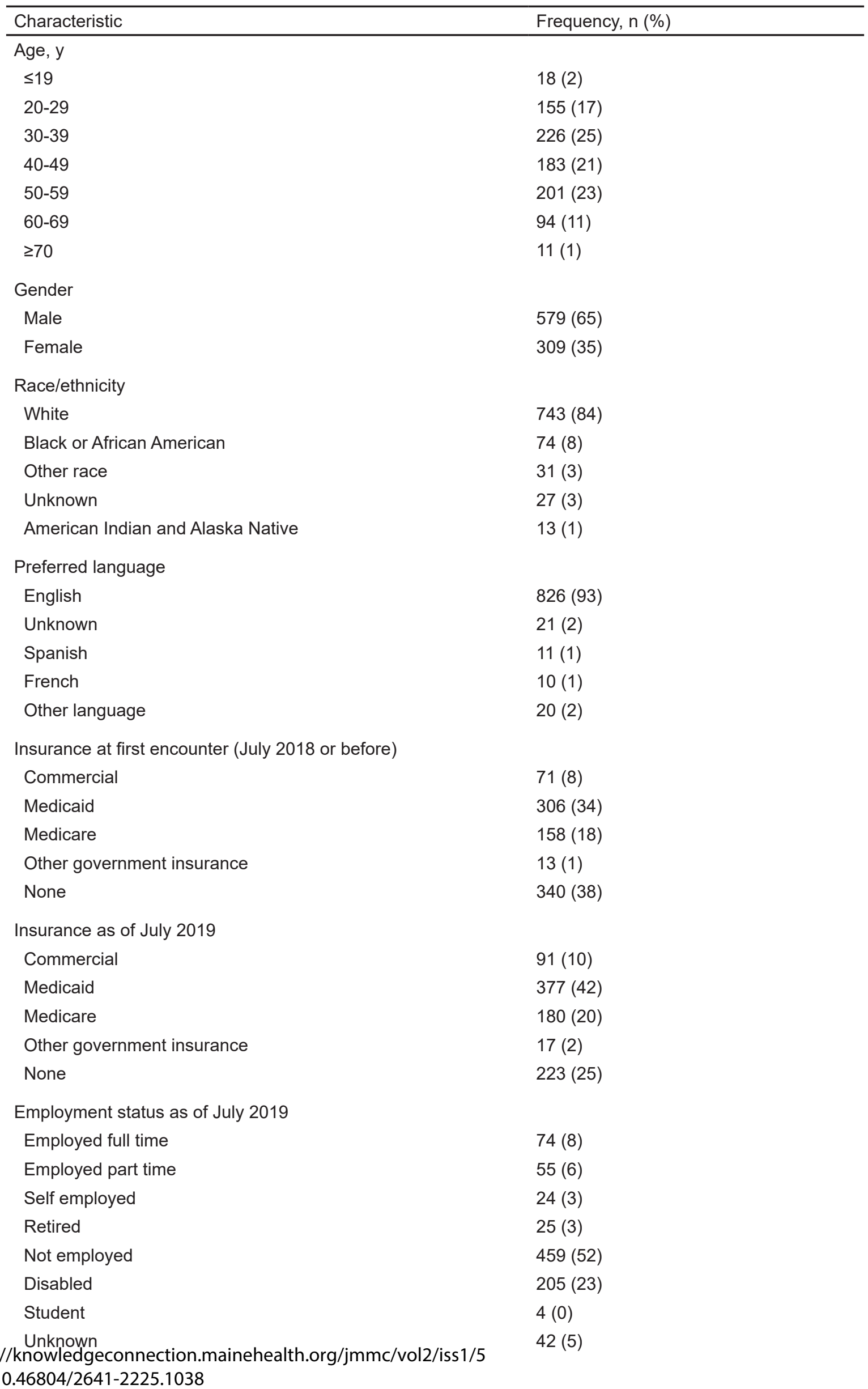


Hemphill et al.: Hospital Utilization and Homelessness: Initial trends observed by the PSLC

Table 2. Patient hospital utilization one year before and after first encounter at the Preble Street Learning Collaborative

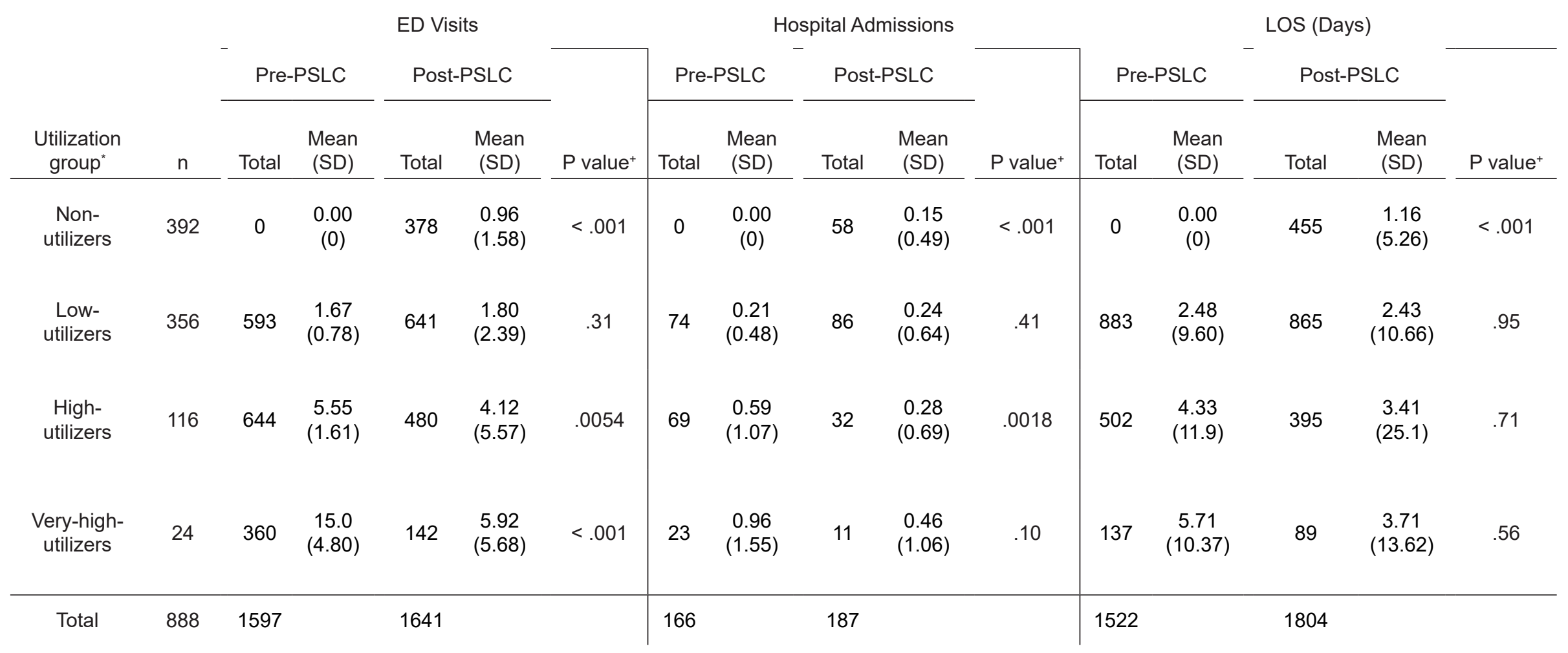

*During the year before the first PSLC encounter, non-utilizers made zero ED visits, low-utilizers made 1-3 visits, high-utilizers made 4-9 visits, and very-high-utilizers made $\geq 10$ visits + Paired t-test

ED, emergency department; LOS, length of stay; PSLC, Preble Street Learning Collaborative; SD, standard deviation. 
a significant decrease in ED visits (15.0 [4.8] to 5.92 [5.68], $P<.001$ ) and did not show significant changes in admissions and LOS.

\section{DISCUSSION}

This study is the first to evaluate changes in hospital utilization by patients experiencing homelessness served by the PSLC's interdisciplinary team. This study focused on a population-based intervention, rather than one targeted to individuals already identified as having complex health and social needs ${ }^{22}$ or as being high-utilizers of the hospital. We demonstrated that both increases and decreases in hospital utilization were associated with engaging in care at a new low-barrier point of entry to health care, as well as intense care coordination within easy reach of the high-risk population. Overall, the study cohort's hospital utilization in all three measures increased between the year before and after engagement with the PSLC. The subgroup analysis revealed decreased ED utilization for highand very-high-utilizers, representing $16 \%$ of the cohort $(n=140)$, after their first engagement with the PSLC. This finding suggests that establishing community-based, low-barrier, interdisciplinary care teams may contribute to more efficient use of the health care system by those experiencing homelessness who use the ED for care at higher rates.

Mean utilization increased for the non-utilizers in all three measures, a key driver for the observed overall increase in utilization across the cohort. We predict that these patients increased their hospital utilization, in part, by the PSLC identifying unmet needs that required emergent care. Also contributory could be the migratory lifestyle of those experiencing homelessness. ${ }^{23}$ For example, new arrivals to the community may not have been seen in the year before their first contact with the PSLC because they received care elsewhere; thus, their hospital utilization could only have increased in the following year.

Another notable finding was the lower proportion of patients who were uninsured at their first PSLC visit (38\%) compared to July 2019 (25\%), which was accompanied by a higher rate of insurance by either Medicare or Medicaid (52\% versus 63\%). Social workers at the PSLC actively assist clients in successfully applying for Medicare and Medicaid coverage. Maine's decision to expand Medicaid during the study period is also notable. This https://knowledgeconnection.mainehealth.org/jmmc/vol2/iss1/5 DOI: $10.46804 / 2641-2225.1038$ change-occurring in January 2019-could have been a major contributor to the observed changes in insurance rates and hospital utilization due to increased connection to health care. ${ }^{24}$

Another limitation of our study was that while we evaluated utilization data from the largest hospital system in our state, we did not include data from smaller regional hospitals and EDs where patients may have received care. Future studies will seek to incorporate these data.

The previously noted transient nature of this population brings another inherent limitation to the study. Our results could have been affected by patients leaving our community. Such patients may appear to have less utilization in the year after their first PSLC encounter because they had left our health care system for another system.

\section{CONCLUSIONS}

The uncertainty of food, shelter, and safety while experiencing homelessness amplifies disease and vulnerability in this population. Our findings illustrate initial success of the PSLC's interdisciplinary team of a nurse practitioner, social workers, and medical, dental, and psychiatric providers in meeting previously unmet needs of the homeless population in Portland, Maine. We correlated increased access to complex coordination of care and decreased hospital utilization for some patients. While the generalizability of these results is not yet known, other health care systems may reduce ED utilization by providing low-barrier access to complex care coordination in clinics specifically focused on serving populations experiencing homelessness.

This study was a short-term look at hospital utilization, an imperfect proxy for acute health care needs. We plan to continue following this cohort, and we predict that, over time, hospital utilization will decrease for all individuals in the cohort. We also plan to study the reasons for ED visits and admissions to the hospital, and if those reasons changed after PSLC engagement. Finally, we hope to identify the specific PSLC interventions that contribute to improved outcomes and decreased hospital utilization for high- and very-high-utilizers. At present, our hypothesis remains that a wellrounded, interdisciplinary team is key. However, it is possible that one or more interventions offered by the PSLC (e.g., intensive medical case management, low-barrier medication-assisted 
treatment for substance use disorder, mental health services) are more effective than others. By identifying the highest-impact interventions, we can design more targeted methods to improve health and advocate for continued institutional support of such endeavors. This study demonstrates early success and opens doors to explore new ways to improve health care for this community.

Acknowledgements: Authors would like to thank Kathleen Fairfield, Tina Holt, Amy Haskins, and Andrew Reed for thier assistance.

\section{Conflicts of Interest: None}

\section{REFERENCES}

1. O'Toole TP, Pollini RA, Ford DE, Bigelow G. The health encounter as a treatable moment for homeless substanceusing adults: the role of homelessness, health seeking behavior, readiness for behavior change and motivation for treatment. Addict Behav. 2008;33(9):1239-1243. doi:10.1016/j.addbeh.2008.04.015

2. Tsai J, Rosenheck RA. Risk factors for ED use among homeless veterans. Am J Emerg Med. 2013;31(5):855-858. doi:10.1016/j.ajem.2013.02.046

3. Lindamer LA, Liu L, Sommerfeld DH, et al. Predisposing, enabling, and need factors associated with high service use in a public mental health system. Adm Policy Ment Health. 2012;39(3):200-209. doi:10.1007/s10488-011-0350-3

4. White BM, Ellis C Jr, Simpson KN. Preventable hospital admissions among the homeless in California: a retrospective analysis of care for ambulatory care sensitive conditions. BMC Health Serv Res. 2014;14:511. doi:10.1186/s12913-014-0511-7

5. Baggett TP, O'Connell JJ, Singer DE, Rigotti NA. The unmet health care needs of homeless adults: a national study. Am J Public Health. 2010;100(7):1326-1333. doi:10.2105/ AJPH.2009.180109

6. Aldridge RW, Story A, Hwang SW, et al. Morbidity and mortality in homeless individuals, prisoners, sex workers, and individuals with substance use disorders in high-income countries: a systematic review and meta-analysis. Lancet. 2018;391(10117):241-250. doi:10.1016/S0140-6736(17)31869-X

7. Bharel M, Lin W-C, Zhang J, O'Connell E, Taube R, Clark RE. Health care utilization patterns of homeless individuals in Boston: preparing for Medicaid expansion under the Affordable Care Act. Am J Public Health. 2013;103 Suppl 2:S311-317. doi:10.2105/ AJPH.2013.301421

8. Wadhera RK, Choi E, Shen C, Yeh RW, Joynt Maddox KE. Trends, Causes, and outcomes of hospitalizations for homeless individuals: a retrospective cohort study. Med Care. 2019;57(1):21-27. doi:10.1097/MLR.0000000000001015

9. Hwang SW, Weaver J, Aubry T, Hoch JS. Hospital costs and length of stay among homeless patients admitted to medical, surgical, and psychiatric services. Med Care. 2011;49(4):350354. doi:10.1097/MLR.0b013e318206c50d
10. Raven MC, Tieu L, Lee CT, Ponath C, Guzman D, Kushel M. Emergency department use in a cohort of older homeless adults: results from the HOPE HOME study. Acad Emerg Med. 2017;24(1):63-74. doi:10.1111/acem.13070

11. Capp R, Rosenthal MS, Desai MM, et al. Characteristics of Medicaid enrollees with frequent ED use. Am J Emerg Med. 2013;31(9):1333-1337. doi:10.1016/j.ajem.2013.05.050

12. Brown RT, Kiely DK, Bharel M, Grande LJ, Mitchell SL. Use of acute care services among older homeless adults. JAMA Intern Med. 2013;173(19):1831-1834. doi:10.1001/ jamainternmed.2013.6627

13. Bell J, Turbow S, George M, Ali MK. Factors associated with high-utilization in a safety net setting. BMC Health Serv Res. 2017;17(1):273. doi:10.1186/s12913-017-2209-0

14. Hwang SW, Chambers C, Chiu S, et al. A comprehensive assessment of health care utilization among homeless adults under a system of universal health insurance. Am J Public Health. 2013;103 Suppl 2(Suppl 2):S294-S301. doi:10.2105/ AJPH.2013.301369

15. Maine Homelessness Survey: 2019 Point in Time Count. Maine State Housing Authority. 2019. https://www.mainehousing.org/ docs/default-source/housing-reports/2019-point-in-time-survey. pdf?sfvrsn=6d6fb415_4. Accessed 23 Nov 2019.

16. Point in Time Survey. Maine State Housing Authority. $2017 . \quad$ https://www.mainehousing.org/docs/default-source/ housing-reports/2017-point-in-time-survey---statewide. pdf?sfvrsn=528ea115_8. Accessed 23 Nov 2019.

17. Institute of Medicine (US) Committee on Health Care for Homeless People. Homelessness, Health, and Human Needs. Washington D.C.: The National Academies Press (US); 1988.

18. Wagner R, Koh N, Bagian J, Weiss K. CLER 2016 National Report of Findings. Issue Brief \#4: Health Care Disparities. Chicago, I.L.: Accreditation Council for Graduate Medical Education; 2016.

19. Bates P, Swann M, Kruithoff K. The Maine Medical CenterPreble Street Learning Collaborative (PSLC): An Example of Community Led Transformation of Care. Journal of Maine Medical Center. 2020 Available at: https://knowledgeconnection. mainehealth.org/jmmc/vol2/iss1/13/. Accessed January 5, 2020.

20. $R$ : A language and environment for statistical computing [computer program]. Vienna, Austria: R Foundation for Statistical Computing; 2017.

21. Giannouchos TV, Kum H-C, Foster MJ, Ohsfeldt RL. Characteristics and predictors of adult frequent emergency department users in the United States: A systematic literature review. J Eval Clin Pract. 2019;25(3):420-433. doi:10.1111/ jep. 13137

22. Hardin L, Kilian A, Muller L, Callison K, Olgren M. Crosscontinuum tool is associated with reduced utilization and cost for frequent high-need users. West J Emerg Med. 2017;18(2):189200. doi:10.5811/westjem.2016.11.31916

23. Metraux S, Treglia D, O'Toole TP. Migration by veterans who received homeless services from the Department of Veterans Affairs. Mil Med. 2016;181(10):1212-1217. doi:10.7205/ MILMED-D-15-00504

24. Miller S. The effect of the Massachusetts reform on health care utilization. Inquiry. 2012;49(4):317-326. doi:10.5034/ inquiryjrnl_49.04.05 